\section{Mysteries of Irritable Bowel Syndrome: Post Infections and Psychophysiological Reactions}

\author{
Hlaing $\mathrm{HH}^{1^{*}}$, Ahmad $\mathrm{U}^{1}$ and Tsai $\mathrm{H}^{2}$ \\ ${ }^{1}$ Registrar, Gastroenterology Department, Hull and East Yorkshire Hospi- \\ tals, NHS Trust, UK
}

${ }^{2}$ Consultant, Gastroenterology Department, Hull and East Yorkshire Hospitals, NHS Trust, UK between the infection of the gastrointestinal tract and Irritable bowel syndrome seems well established based on clinical, epidemiological data and animal models.

Sir Arthur Hurst (1943) introduced a term "Post-dysenteric colonic irritability" and it mentioned the persistent irritability of the bowel following an acute attack of bacillary or amoebic dysentery [1]. The later symptoms which persisted after the infection died out were assumed as functional irritability of the colon [1]. Stewart described 2 types of post dysenteric colitis and type 1 which accounts for $55 \%$ and associated mostly with diarrhoea which is intermittent, seldom severe and sometimes morning symptoms with no organic changes in colon [2]. In some cases psychological factors noted with symptoms. These cases were self-limiting and less severe with slow natural improvement without much treatment [2]. However, type 2 post dysenteric colitis is associated with more inflammatory response and more severe outcome with the requirement for extensive treatment [2]. It is documented that $3 \%$ to $36 \%$ of gastrointestinal infections are associated with new onset IBS symptoms and bacterial, protozoal and helminthic infections are associated with more prolonged symptoms [3]. In 1962, Chaudhury and Truelove carried out observational study in 130 patients with irritable colon syndrome and noted that the syndrome has strongly linked to previous history of dysentery and post dysenteric group has more favorable outcome than others [4].

\section{Risk Factors and Associations}

There are many risk factors which are identified to be associated with post infectious irritable bowel syndrome. It includes prolonged duration of initial illness, toxicity of infecting bacterial strain, smoking, mucosal markers of inflammation, female gender, depression, hypochondriasis and adverse life events in the preceding 3 months [3]. A systematic review and meta-analysis revealed that the odds developing irritable bowel syndrome increased six fold after bowel infections and young age, prolonged fever, anxiety and depression are associated risk factors [5]. Host factors; female gender (relative risk2.9) and advancing age seem to have modest degree of protection [6]. Interestingly, patients who presented with vomiting were less likely to develop persistent bowel symptoms and may even be protective due to reduce infecting dose [6]. The more severe the attack of infection and inflammation, the longer the symptoms and reaction with persistently increasing concentration of inflammatory cytokines like interleukin 1[6].

\section{Epidemiology of Post Infectious Irritable Bowel Syndrome}

Post infectious IBS is associated with more virulent organisms like Campylobacter jejuni and E. Coli $\mathrm{O} 157: \mathrm{H} 7$ which are associated with mucosal ulceration [7]. The highest incidence of PI-IBS was seen in the cases after the dual infection with C. Jejuni and E. coli O157: H7 and which was $36 \%$ after 24 months of post infection [3]. In 1993, a study was done in 38 patients following infection with salmonella food poisoning and it was found out that $31 \%$ are associated with PI-IBS symptoms fulfilling ROME 3 criteria with female predominance [7]. A prospective cohort study was done in the subjects after 
infection with Salmonella enteritidis and questionnaires were asked in 481 cases and 547 controls and it was found out that cumulative incidence of IBS in 12 months after infection was $11.6 \%$ in cases and $1.5 \%$ in controls with significant relative risk of 7.8 [8]. A large cohort study (Walkerton Health Study) was done in 2002 which was 2 years after outbreak of acute E. coli O157: $\mathrm{H} 7$ and Campylobacter Jejuni infection following contamination of municipal water supply [9]. Among 2069 participants, ROME I criteria were met in 71 of 701 controls $(10.1 \%)$ and 249 of 904 subjects $(27.5 \%)$ in self-reported gastroenteritis and 168 of 464 subjects $(36.2 \%)$ with clinically suspected gastroenteritis $(\mathrm{p}<001)$ [9].

The prevalence of the symptoms of post infectious IBS after norovirus infection was carried out in the Canada and it was found out that 21 of $89(23.6 \%)$ had symptoms of post infectious IBS (ROME 1 criteria) at 3 months after infection compared to $3.4 \%$ of those who were well during outbreak but the prevalence among cases and controls was not significantly different in 6,12 and 24 months post infection [10]. It is concluded that the IBS symptoms are more transient after viral infections [10]. There was a large prospective cohort study in 1252 subjects following 6 years after lab-confirmed Giardia infection and it was found out that $39.4 \%$ of cases were met ROME III criteria for IBS which was significantly elevated compared to controls. It was concluded that intestinal protozoan infections are associated with long term and slow self-limiting complications [11]. The risks of IBS have been found to increase in patients following enteric infections in Western countries and travelers' diarrhea coming back from developing countries [12].

\section{Clinical Features of Post Infectious IBS}

ROME III criteria for IBS mentioned that recurrent abdominal pain or discomfort at least 3 days/month in the last 3 months associated with two or more of the followings: Improvement with defecation, Onset associated with a change in frequency of stool, Onset associated with a change in form (appearance) of stool. The diagnosis of post infectious IBS was considered in the patients who have no previous history of IBS in the studies. Most of the studies were done 3 months to 6 years post infection in previously asymptomatic individuals.

Post infectious IBS was found to have more diarrheal symptoms compared to non-infectious IBS. A six year follow up study after post infectious IBS was done by Neal et al., and comparing 14 PI-IBS with 20 new IBS, it was found out that PI-IBS had significantly more days with loose stools $(p<0.005)$ but a similar number of days with pain, urgency and bloating though large number needed to confirm that [13].

\section{Pathophysiology of Post Infectious IBS}

There are several factors which can contribute to the pathophysiology of post infectious IBS. A study which was done in 2000 by Spiller et al., revealed that the number of enteroendocrine cells and $\mathrm{T}$ lymphocytes in rectal biopsies increased along with increasing gut permeability in acute infection following Campylobacter enteritis and it can persist for more than one year which contributes to post dysenteric IBS [14]. The gut motility and secretion are related to serotonin (5-HT) which releases from enterochromaffin cells and both UC and IBS are associated with similar molecular changes in serotonergic signaling mechanisms [15]. A study which was done in PI-IBS and IBS-C patients matched with controls to monitor post prandial
5 HT level revealed that PI-IBS patients have significantly higher peak post prandial 5 HT values than patients with IBS-C and controls [16].

In 1993, a study of changes in anorectal function was done in patients who had chronic persistent symptoms 2 years after Salmonella infection revealed that all patients had increased rectal sensitivity and decreased rectal compliance [17]. A study done by Kanazawa et al., in 2014 which is a comparative study between PI-IBS and Non PI-IBS mentioned that PI-IBS has greater colonic hypercontractility than non PI-IBS and speculated that mild mucosal inflammation may cause that problem [18].

There is a study regarding the possibility of genetic predisposition in post infectious IBS done by Alexandra-Chloe' Villani et al., in 2001 and it mentioned that four genetic variants were likely to be associated with PI-IBS though it is not significant after correction for number of single nucleotide polymorphism. Two of them are located in TLR9 which are pattern recognition receptors and one in CDH1 encodes tight junction protein and the other in IL-6, cytokines. It was concluded that genes which are responsible for encoding proteins for epithelial cell barrier function and innate immune response are associated with post infectious IBS [19]. Regarding the concept of microbiota in post infectious IBS, current data with limited number of patients could not define any entire phylogenetic for PI-IBS though it supports the idea that the alterations in commensal proportion which can in turn affect the overall microbiological picture [20]. However, psychological factors found out to have as a precipitation to the PIIBS as stress can increase intestinal permeability and depression can lower the threshold to inflammatory response $[21,22]$.

Infectious gastroenteritis can result in Post-Infectious Malabsorption Syndrome (PI-MAS) known as tropical sprue and in turn PI-MAS can link to Small Intestinal Bacterial Overgrowth (SIBO). There are also some suggestions that SIBO can link to diarrhoea predominant IBS as in PI-IBS [23]. However, a systematic review and meta analysis showed the role of testing in SIBO in IBS patients remains unclear [24].

\section{Treatment of Post Infectious IBS}

There are many treatment modalities which had been tried in PIIBS like steroids, mesalazine, probiotics and dietary modifications. A study was done in 29 patients with PI-IBS regarding the response to oral Prednisolone $30 \mathrm{mg}$ /day for 3 weeks and it did not improve the symptoms and intestinal enterochromaffin cells were not reduced though T-lymphocytes counts decreased $[25,26]$. There was a study based on both post infectious IBS and non infective IBS regarding Mesalazine therapy which has anti-inflammatory effects. It included 61 patients who met ROME III criteria for IBS with diarrhea predominant features and 18 and 43 for PI-IBS and non infective IBS respectively. They were given Mesalazine $800 \mathrm{mg} 3$ times/day for 30 days and it was found out that both groups had significant reduction in total symptom score, stool frequency, consistency, abdominal pain and discomfort and all were statistically significant with $\mathrm{P}<0.0001$. There were no differences in response between these two groups [27].

There were some studies which were done in dietary implications like FODMAP in IBS and found out to have symptom improvements but these are not limited to post infectious IBS and mostly generalized IBS. As general IBS patients, individual sensitivity of diet plays a 
Citation: Hlaing HH, Ahmad U, Tsai H (2018) Mysteries of Irritable Bowel Syndrome: Post Infections and Psychophysiological Reactions. J Gastroenterol Hepatology Res 3: 021 .

role in post-infectious IBS patients and tailored dietary advice with low FODMAP diets and probiotics can change the microbiota composition and regulates the gastrointestinal endocrine cells $[28,29]$. Based on the hypothesis that the IBS is associated with Small Intestinal Bacterial Overgrowth [SIBO], the symptoms improvement was assessed after treatment of SIBO and it showed significant reduction [30]. In 2006, a study which was based on non-absorbable oral antibiotic Rifaximin $400 \mathrm{mg}$ three times daily for 10 days given to IBS patients and global improvement scale was measured for 10 weeks after discontinuation. Symptom improvement was seen up to 10 weeks after discontinuation of treatment though the study has limitations of modest sample size, short duration and patients were from one centre [31]. As the post infectious IBS can follow traveler's diarrhea and has impaction on long term morbidity, there were two studies which use Rifaximin to prevent traveler's diarrhea. Both were randomized double-blinded, placebo controlled trials and they showed that Rifaximin was effective and well tolerated with minimal alteration of faecal flora $[32,33]$. However, the possibility of preventing PI-IBS in long term needs more evaluation [12]. In diarrhea predominant IBS, 5 HT3 receptor antagonist, alosetron, was recently approved only for female diarrhea predominant IBS in US but only for limited prescriptions due to side effects of severe constipation, ischaemic colitis and bowel perforation. It is based on serotonin pathway causing enhancement in small intestinal absorption, slow colonic transit and reduces visceral pain [34]. There is a study which reviewed the records of 70 patients with Clostridium difficile infection who had faecal microbiota transplantation and it showed that faecal microbiota transplantation through colonoscopy seems an effective treatment option for recurrent and virulent $C$. Diff infection with post-infectious bowel symptoms [35]. The use of central neuromodulators in functional bowel disorders based on the hypothesis of brain-gut interaction was published recently as ROME foundation working team report though it is under the process of further refinement [36].

\section{Conclusion}

Post infectious IBS is a long term debilitating condition with not very promising treatment options at the moment. It is likely preventable if the infection can be prevented and the researches regarding this condition might need to explore further bearing in mind about emergence of antimicrobial resistance all over the world. It is also an area that still needs addressing in depth relating pathophysiological mechanisms and treatment modalities. Moreover, multidisciplinary involvement in developing consensus guideline is important. As there can be different microbiota composition with variant strains of infection in different population, the new concept of ROME IV which based on multicultural focus hope to get more solutions for such subtypes of IBS.

\section{References}

1. Powell SJ, Wilmot AJ (1966) Ulcerative Post-dysenteric Colitis. Gut 7: 438-443.

2. Stewart GT (1950) Post-dysenteric Colitis. Br Med J 1: 405-409.

3. Spiller R, Garsed K (2009) Postinfectious Irritable Bowel Syndrome. Gastroenterology 136: 1979-1988.

4. Chaudhary Na, Truelove Sc (1962) The Irritable Colon Syndrome. A Study Of The Clinical Features, Predisposing Causes, And Prognosis In 130 Cases. Q J Med 31: 307-322.
5. Thabane M, Kottachchi DT, Marshall JK (2007) Systematic review and meta-analysis: The incidence and prognosis of post-infectious irritable bowel syndrome. Aliment Pharmacol Ther 26: 535-544.

6. Neal KR, Hebden J, Spiller R (1997) Prevalence of gastrointestinal symptoms six months after bacterial gastroenteritis and risk factors for development of the irritable bowel syndrome: postal survey of patients. BMJ 314: $779-782$.

7. McKendrick MW, Read NW (1994) Irritable bowel syndrome--post salmonella infection. J Infect 29: 1-3.

8. Mearin F, Perez-Oliveras M, Perello A, Vinyet J, Ibañez A, et al. (2005) Dyspepsia and irritable bowel syndrome after a Salmonella gastroenteritis outbreak: one-year follow-up cohort study. Gastroenterology 129: 98-104.

9. Marshall JK, Thabane M, Garg AX, Clark WF, Salvadori M, et al. (2006) Incidence and epidemiology of irritable bowel syndrome after a large waterborne outbreak of bacterial dysentery. Gastroenterology 131: 445-450.

10. Marshall JK, Thabane M, Borgaonkar MR, James C. Postinfectious irritable bowel syndrome after a food-borne outbreak of acute gastroenteritis attributed to a viral pathogen. Clin Gastroenterol Hepatol 5: 457-460.

11. Hanevik K, Wensaas KA, Rortveit G, Eide GE, Mørch K, et al. (2014) Irritable bowel syndrome and chronic fatigue 6 years after giardia infection: a controlled prospective cohort study. Clin Infect Dis 59: 1394-1400.

12. Ericsson CD, Hatz C, DuPont AW (2008) Postinfectious Irritable Bowel Syndrome. Clinical Infectious Diseases 46: 594-599.

13. Neal KR, Barker L, Spiller RC (2002) Irritable bowel syndrome and the enteric nervous system, Prognosis in post-infective irritable bowel syndrome: a six year follow up study. Gut 51: 410-413.

14. Spiller RC, Jenkins D, Thornley JP, Hebden JM, Wright T, et al. (2000) Increased rectal mucosal enteroendocrine cells, T lymphocytes, and increased gut permeability following acute Campylobacter enteritis and in post-dysenteric irritable bowel syndrome. Gut 47: 804-811.

15. Coates MD, Mahoney CR, Linden DR, Sampson JE, Chen J, et al. (2004) Molecular defects in mucosal serotonin content and decreased serotonin reuptake transporter in ulcerative colitis and irritable bowel syndrome. Gastroenterology 126: 1657-1664.

16. Dunlop SP, Coleman NS, Blackshaw E, Perkins AC, Singh G, et al. (2005) Abnormalities of 5-hydroxytryptamine metabolism in irritable bowel syndrome. Clin Gastroenterol Hepatol 3: 349-357.

17. Bergin AJ, Donnelly TC, McKendrick MW, Nicholas WR (1993) Changes in anorectal function in persistent bowel disturbance following salmonella gastroenteritis. European Journal of Gastroenterology \& Hepatology 5: 617-620.

18. Kanazawa M, Palsson OS, van Tilburg MA, Gangarosa LM, Fukudo S, et al. (2014) Motility response to colonic distention is increased in postinfectious irritable bowel syndrome (PI-IBS). 26: 696-704.

19. Villani AC, Lemire M, Thabane M, Belisle A, Geneau G, et al. (2010) Genetic risk factors for post-infectious irritable bowel syndrome following a waterborne outbreak of gastroenteritis. Gastroenterology 138:1502-1513.

20. Salonen A, de Vos WM, Palva A (2010) Gastrointestinal microbiota in irritable bowel syndrome: present state and perspectives. Microbiology 156 : 3205-3215.

21. Söderholm JD, Perdue MH (2001) Stress and gastrointestinal tract. II. Stress and intestinal barrier function. Am J Physiol Gastrointest Liver Physiol 280: 7-13.

22. Ghia JE, Blennerhassett P, Collins SM (2008) Impaired parasympathetic function increases susceptibility to inflammatory bowel disease in a mouse model of depression. J Clin Invest 118: 2209-2218. 
23. Ghoshal UC, Gwee KA (2017) Post-infectious IBS, tropical sprue and small intestinal bacterial overgrowth: the missing link. Nat Rev Gastroenterol Hepatol 14: 435-441.

24. Ford AC, Spiegel BM, Talley NJ, Moayyedi P (2009) Small intestinal bacterial overgrowth in irritable bowel syndrome: systematic review and meta-analysis. Clin Gastroenterol Hepatol 7: 1279-1286.

25. Dunlop SP, Jenkins D, Neal KR, Naesdal J, Borgaonker M, et al. (2003) Randomized, double-blind, placebo-controlled trial of prednisolone in post-infectious irritable bowel syndrome. Aliment Pharmacol Ther 18: 7784.

26. Collins SM, Chang C, Mearin F (2012) Postinfectious Chronic Gut Dysfunction: From Bench to Bedside. Am J Gastroenterol Suppl 1: 2-8.

27. Bafutto M, Almeida JR, Leite NV, Oliveira EC, Gabriel-Neto S, et al (2011) Treatment of postinfectious irritable bowel syndrome and noninfective irritable bowel syndrome with mesalazine. Arq Gastroenterol 48 : 36-40.

28. El-Salhy M, Gundersen D (2015) Diet in irritable bowel syndrome. Nutrition Journal 14: 36.

29. Iacob T, Ţăţulescu DF, Dumitraşcu DL (2017) Therapy of the postinfectious irritable bowel syndrome: an update. Clujul Med 90: 133-138.
30. Pimentel M, Chow EJ, Lin HC (2000) Eradication of small intestinal bacterial overgrowth reduces symptoms of irritable bowel syndrome. Am J Gastroenterol 95: 3503-3506.

31. Pimentel M, Park S, Mirocha J, Kane SV, Kong Y (2006) The effect of a nonabsorbed oral antibiotic (rifaximin) on the symptoms of the irritable bowel syndrome: a randomized trial. Ann Intern Med 145: 557-563.

32. DuPont HL, Jiang ZD, Okhuysen PC, Ericsson CD, de la Cabada FJ, et al. (2005) A randomized, double-blind, placebo-controlled trial of rifaximin to prevent travelers' diarrhea. Ann Intern Med 142: 805-812.

33. Taylor DN, McKenzie R, Durbin A, Carpenter C, Atzinger CB, et al.( 2006) Rifaximin, a nonabsorbed oral antibiotic, prevents shigellosis after experimental challenge. Clin Infect Dis 42: 1283-1288.

34. De Ponti F, Tonini M (2001) Irritable bowel syndrome: new agents targeting serotonin receptor subtypes. Drugs 61: 317-332.

35. Mattila E, Uusitalo-Seppälä R, Wuorela M, Lehtola L, Nurmi H, et al. ( 2012) Fecal transplantation, through colonoscopy, is effective therapy for recurrent Clostridium difficile infection. Gastroenterology 142: 490-496.

36. Drossman DA, Tack J, Ford AC, Szigethy E, Törnblom H, et al. (2018) Neuromodulators for Functional Gastrointestinal Disorders (Disorders of Gut-Brain Interaction): A Rome Foundation Working Team Report. Gastroenterology 154: 1140-1171. 


\section{H \\ нетан上}

Addiction \& Addictive Disorders

Advances in Industrial Biotechnology

Advances in Microbiology Research

Agronomy and Agricultural Science

AIDS Clinical Research \& STDs

Alcoholism, Drug Abuse \& Substance Dependence

Allergy Disorders and Therapy

Alternative, Complementary \& Integrative Medicine

Alzheimer's \& Neurodegenerative Diseases

Anesthesia \& Clinical care

Angiology \& Vascular Surgery

Animal Research and Veterinary Science

Aquaculture \& Fisheries

Archives of Urology

Archives of Zoological Studies

Atmospheric \& Earth Sciences

Biotech Research \& Biochemistry

Brain \& Neuroscience Research

Cancer Biology and Treatment

Cardiology and Neurocardiovascular Diseases

Cell Biology \& Cell Metabolism

Clinical Dermatology and Therapy

Clinical Immunolgy \& Immunotherapy

Clinical Studies and Medical Case Reports

Community Medicine \& Public Health Care

Current Trends: Medical \& Biological Engineering

Cytology \& Tissue Biology

Dentistry: Oral Health \& Cosmesis

Diabetes \& Metabolic Syndrome Disorders

Emergency Medicine, Trauma and Surgical Care

Environmental Science: Current Research

Food Science \& Nutrition

Forensic, Legal \& Investigative Sciences

Gastroenterology \& Hepatology Research
Genetics \& Genomic Sciences

Gerontology \& Geriatric Medicine

Hematology, Blood Transfusion \& Disorders

Hospice \& Palliative Medical Care

Human Endocrinology

Infectious \& Non Infectious Diseases

Internal Medicine and Primary HealthCare

Laser Research \& Applications

Medicine: Study \& Research

Modern Chemical Sciences

Nanotechnology: Nanomedicine \& Nanobiotechnology

Neonatology and Clinical Pediatrics

Nephrology \& Renal Therapy

Non-invasive Vascular Investigations

Nuclear Medicine, Radiology \& Radiation Therapy

Obesity \& Weight Loss

Ophthalmology \& Clinical Research

Orthopedic Research \& Physiotherapy

Otolaryngology, Head and Neck Surgery

Pathology: Clinical \& Medical Research

Pharmacology, Pharmaceutics \& Pharmacovigilance

Physical Medicine, Rehabilitation \& Disabilities

Plant Science: Current Research

Practical and Professional Nursing

Protein Research \& Bioinformatics

Psychiatry, Depression and Anxiety

Pulmonary Medicine \& Respiratory Research

Reproductive Medicine, Gynaecology and Obstetrics

Stem Cells Research, Development \& Therapy

Surgery: Current Trends \& Innovations

Toxicology: Current Research

Translational Science and Research

Vaccines Research and Vaccination

Virology \& Antivirals 